\title{
Quality of agile adoption in global software development: An assessment model
}

\author{
Mahnaz Afshari ${ }^{1}$, Taghi Javdani Gandomani ${ }^{2}$ \\ ${ }^{1}$ Department of Computer Engineering, Isfahan Branch, Islamic Azad University, Isfahan, Iran \\ ${ }^{2}$ Department of Computer Science, Shahrekord University, Shahrekord, Iran
}

\begin{tabular}{l} 
Article Info \\
\hline Article history: \\
Received May 28, 2020 \\
Revised Jul 14, 2020 \\
Accepted Jul 24, 2020 \\
\hline Keywords: \\
Agile adoption \\
Agile software development \\
Agile methods \\
Assessment model \\
Global software development
\end{tabular}

\section{Article Info}

Article history

Received May 28, 2020

Revised Jul 14, 2020

Accepted Jul 24, 2020

Global software development

\begin{abstract}
Over the last decade, software development has faced two approaches to Agile and global software development (GSD). While Agile development is focused on the reduction of software development overhead by reducing the distance between individuals and face-to-face communications, in global software development, the use of human power in various sites is considered. Despite their inherent differences, the combination of these two approaches has received considerable attention from researchers and software professionals. Meanwhile, the lack of a model or tool capable of assessing teams' adaptation to Agile methods seems to be a research gap. The current research aims to solve this challenge by proposing a model in this regard. Considering the major related factors and weighting them, this model allows software teams to assess the rate of their adaptation and success in global software development.
\end{abstract}

This is an open access article under the $\underline{C C B Y-S A}$ license.

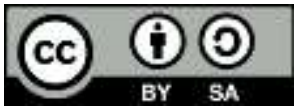

\section{Corresponding Author:}

Taghi Javdani Gandomani

Department of Computer Science

Shahrekord University

Rahbar Blvd., Shahrekord, Iran

Email: javdani@sku.ac.ir

\section{INTRODUCTION}

During the past decades, software engineering has undergone several changes each of which has opened a new avenue to the software development process. Meanwhile, the advent of the Internet and several Internet-based software services caused the demand for software products to increase significantly. Over recent years, the software market has tended toward the fast delivery of software products. Accordingly, the application of new approaches, as well as efficient technical techniques has received lots of attention from software teams and companies.

In recent years, two new approaches have been considered in software development. The first approach is Agile software development (ASD) and the second is GSD. In the early $21^{\text {st }}$ century, new methods of software development called Agile methods were introduced to the industry [1]. Unlike traditional methods, these methods created completely different values and characteristics in software development [2]. Agile values remove precise agreements and replace them with flexibility in changes acceptance.

Additionally, they put individuals and human interactions versus processes and tools and replace heavy documentations with workable software. In these methods, not only the customer is not against the team, but also as a member of the development team and besides them helps with high-quality product development.

On the other hand, with the advent of the Internet and the possibility of remote accesses, development processes have also undergone changes. The development teams, which were busy with performing their duties in a place, were dispersed, and the possibility to use the capabilities and expertise of individuals in a team, each 
of them lived in a corner of the world, was provided. This way, the possibility of remote production of software was provided and the global and distributed development methods were created [3]. The advantages of GSD methods, such as employing individuals with various skills and capabilities, the reduction of development costs and time have encouraged software teams to use these methods.

The advantages of GSD methods have led to the interest of software development companies in this approach, and as developers are highly interested in Agile methods, the use of Agile methods in the GSD was proposed [4]. Considering differences and sometimes the contradictions of these two categories in nature and concept, the combination of them has received attention as a challenge. For example, the Agile approach has emphasized the deployment of a development team in a place, while this is exactly the basis of the GSD definition. Therefore, at the first glance, the composition of this contradiction seems impossible [5], but researchers and professionals in this area have made attempts to put in practice the solutions for Agile deployment and proposed various methods.

After presenting strategies and methods for GSD using Agile methods, the need to study the quality level of Agile methods deployment and the rate of adaptation to them was proposed in the GSD so that companies and development teams can assess the rate of their success in adapting and using Agile methods in global teams and try to make the deployment process better. Research studies conducted in this area show that there is no qualitative model or tool to measure the degree of companies' adaptation to these methods in distributed settings or the success of deploying these methods in these settings. Therefore, attempts were made in this study to propose an appropriate assessment model in this area in order to resolve this challenge.

The rest of this paper is organized as follows: Section 2 has to do with the introduction of GSD and ASD and their important aspects. Section 3 is dedicated to the introduction of the most important related works. Section 4 presents the performed stages of this study. The obtained results and the proposed model are analyzed in Section 5. Finally, a brief conclusion of the study is presented in Section 6.

\section{BACKGROUND}

The GSD and Agile global software development (AGSD) are two concepts that have somehow received attention over the past years. In the following, these two approaches are introduced and their different aspects are shown.

\subsection{GSD}

Over recent years, the software has become an integral part of businesses and the lives of communities' individuals. About one decade ago, following the endeavor to reduce costs and access to individuals' skills, software development companies turned to remote software development. Companies can now use the skills of specialists and professionals all around the world.

The GSD was proposed in the early $21^{\text {st }}$ century and caused changes in the software industry area [6]. Software companies and organizations tended to use global resources and time intervals to improve productivity and efficiency. Resources such as high-level synchronous communication tools, including phones and instant messages [7], or non-synchronous tools such as email, as well as recent technologies to develop offsite communications as quickly as possible have become available in recent years [8]. This encourages companies and organizations to make use of the benefits of GSD. The aim of software companies is to produce higher quality products with lower development costs and increase business productivity, and the GSD will make it faster and easier to attain this goal.

There are several advantages to GSD, most notably the reduction of costs, access to a wide range of multi-skilled workforce, reduction of market-entry time, proximity to market and customer, and sharing knowledge and experiences [9]. In addition to the above-mentioned advantages, several challenges have been mentioned in this regard. The most important of these challenges are the geographical distance, cultural differences, inappropriate interactions, and language differences [10,11].

\subsection{AGSD}

In the $21^{\text {st }}$ century, the software was seriously affected by globalization. The computer companies were quickly interested in this area and set targets such as the reduction of costs, access to a skilled workforce, etc., and began their endeavor to resolve the inherent challenges of this paradigm [6]. Parallel to the tendency toward GSD, the software industry has also tended toward Agile methods in recent years and with the introduction of Agile methods [12]. GSD and ASD are two approaches in the area of software in the 21st century. Considering several advantages of the above-mentioned approaches, the use of Agile methods and their practices in the area of GSD was introduced as AGSD [13, 14]. Some researchers have investigated the application of Agile practices in the area of GSD and stated its strengths and weaknesses [15].

The GSD achievements in software development had to a large extent embraced the concepts of lightweight techniques. The characteristics of Agile methodologies such as lightweight documentation, short 
iterations, rapid broadcasting, sprints, the use of evolutionary concepts, and support for constructive interactions in GSD settings lead to better results [16]. The above-mentioned characteristics for Agile methods on the one hand, and the advantages offered by GSD to the software production industry like e.g., employing skilled workforce, reduction of costs, knowledge sharing, etc., on the other hand, led to a tendency toward taking advantage from both concepts simultaneously.

From another perspective, in GSD methods, team's individuals are not only geographically away, but also differ in terms of time delay, and socio-cultural and sometimes political differences. These are inconsistent with Agile principles which always emphasize on integrated setting and the team deployed in a place [17]. Agile teams believe in the presence of team members in a commonplace with small numbers because Agile thought believes in face to face interactions, but in global development teams, this is simply not possible because geographical distances of members inhibit the incidence of this important issue. Additionally, these geographical distances challenge the possibility of forming a team at a common place [18]. In addition to these cases, it is necessary to consider challenges caused by time, geographical, and cultural differences which may lead to the uncertainty felt by team members on the one hand, and the difficulty in establishing a relationship on the other hand. Despite the above, some researchers believe that the combination of these two categories and the use of the added value resulting from the combination of these two concepts are difficult [19].

Agile methodologies believe in continuous iterations and the production of multiple versions of software products, and this may make it difficult and complicated the possibility to use these methods globally $[11,20]$. It is difficult to hold regular daily meetings to control the ready to release version in a distributed team because the coordination between team members to participate in daily meetings is very difficult due to time differences. This is felt more when there are many time differences. In the view of Leffingwell [21], the use of Agile methods in the global and large teams working on projects with a long life span is not suitable.

Certainly, there are some problems and limitations to the use of Agile methods in GSD teams $[11,22]$, but a large number of companies tend to use this opportunity despite these challenges, and some of them have used these opportunities and good results have been achieved $[8,13,21]$. What is important is that in what areas the companies should try to achieve better success.

\section{RELATED WORKS}

At first glance, the integration of Agile methods and GSD may seem strange and impossible, and many challenges may lie ahead of this path [3]. For example, one of the challenges is that Agile methods emphasize the close interactions and communications of team members with each other and the customer, while GSD points to the lack of team deployment and focus in a region. Besides several studies pointing to the challenges of AGSD [23-25], some researchers have also proposed solutions to use the Agile approach in GSD. It should be noted that AGSD is subject to the challenges reported for ASD too and providing the facilitators proposed for ASD would be beneficial for AGSD too [26-29].

Among research studies done in the area of employing the Agile approach in distributed development teams, we can refer to [30]. In this study, the authors did a comparative study in Agile methods. Among this paper's achievements were the presentation of some practices for Agile deployment in the GSD. These practices include certain working hours, the use of multiple strong communication channels between team members in order to strengthen interactions such as social networks and written, audio, and video conversation infrastructures, and formation of working teams with the close geographical area for maximum coordination.

In another study, the authors investigated the problems under discussion in the GSD using the Agile method and discussed this problem from the perspective of geographical distances [3]. At first, they addressed some challenges such as limited interactions, failure to communicate in the face to face form, etc., and then, presented a framework to solve these problems. They suggested that translation and interpretation tools are used to resolve the problems caused by language differences, and electronic tools such as chat panels are used to resolve reaction problems.

Vallon et al. [31] conducted a systematic review in order to investigate practices affecting the AGSD from 1999 until 2016 and determined the most important of them. The results of their study showed that scrum methods and the combination of scrum and XP are the most popular Agile methods. Additionally, from 1999 to 2009, XP exercises have been the most widely used Agile practices, while in a period between 2010 and 2016, scrum as the most important Agile method has been used in the area of GSD, and some of its practices were used toward Agile deployment in the GSD.

In their research study, Kalluri et al. [32], investigated the role of Agile methods in the GSD and studied the advantages and challenges in this regard. In his study, they have expressed some effective practices in the deployment of Agile in global development teams. Some of the effective practices are pair programming, short broadcasting, customer feedbacks, and requirements gathering. 
In another study conducted by Vallon et al. [33], a framework was proposed for AGSD. The framework mentioned in this study has been presented in three categories, and in sum, it has used 29 Agile practices. Additionally, this framework includes 10 guidelines. Based on geographical regions, the classification intended by this study includes three groups of 1- two sites in a city, 2- two sites in different cities of one country, and 3- three sites in different countries of the Europe continent.

In their research study conducted in 2018, Lampropoulos and Siakas [34] introduced the best practices toward Agile distributed teams with a communication approach. In their research study, they pointed to self-organization, short broadcasting, small teams, the use of social networks and communication applications and acceptance of multicultural education as practices that are suitable for the configuration of global development teams. They also pointed to challenges lying ahead of communication in global Agile development teams and proposed some solutions to resolve them like e.g., holding daily meetings using audio and video tools in the social networks to make the team members more familiar with each other and to create the feeling of being in a single team.

Estler et al. [35] conducted an experimental study on global industrial projects. They divided the projects into two groups of Agile and structured groups and investigated their related data. They found that the project and development team will face no challenge by the use of Agile methods instead of structured methods. Their criteria in this comparison were synchronous interactions, team motivation, and the costs of the project.

As countries such as Pakistan, India, and Malaysia are countries active in the area of GSD, Tahir and Menarvi [36] investigated the GSD challenges in their study using the Agile method and proposed a solution to resolve the problems. In their solution, they considered cultural, geographical, and structural similarities and general grounds to reduce the effect of challenges. Some of the studies are expressed in brief in Table 1.

Table 1. The most important studies conducted on the improvement of GASD deployment

\begin{tabular}{|c|c|c|c|}
\hline Ref. & Research topic & Research achievement & Weaknesses \\
\hline [23] & $\begin{array}{c}\text { challenges of integration of Agile } \\
\text { and GSD }\end{array}$ & $\begin{array}{c}\text { investigation of challenges in Agile software } \\
\text { development, such as face-to-face communication } \\
\text { versus telecommunications }\end{array}$ & $\begin{array}{l}\text { failure to present solutions to } \\
\text { resolve the challenges }\end{array}$ \\
\hline [36] & investigation of GSD challenges & $\begin{array}{c}\text { proposing a solution to reduce the effect of } \\
\text { challenges given the cultural and geographical } \\
\text { aspect }\end{array}$ & $\begin{array}{l}\text { lack of attention to all aspects of } \\
\text { GASD }\end{array}$ \\
\hline$[30]$ & $\begin{array}{l}\text { comparative study on Agile } \\
\text { practices in the GSD using } \\
\text { communication approach }\end{array}$ & $\begin{array}{l}\text { proposing effective Agile practices in the area of } \\
\text { interactions and communications }\end{array}$ & $\begin{array}{l}\text { failure to propose a framework } \\
\text { showing how to use practices }\end{array}$ \\
\hline [31] & $\begin{array}{l}\text { investigating Agile effective } \\
\text { practices in the GSD }\end{array}$ & $\begin{array}{l}\text { presenting the most important and most popular } \\
\text { Agile methods used in the GSD }\end{array}$ & $\begin{array}{l}\text { the paper is only a literature } \\
\text { review and has no practical } \\
\text { achievement }\end{array}$ \\
\hline [32] & $\begin{array}{l}\text { the role of Agile methods in the } \\
\text { GSD }\end{array}$ & proposing effective practices in the research area & $\begin{array}{l}\text { failure to determine how to apply } \\
\text { Agile practices }\end{array}$ \\
\hline [33] & $\begin{array}{l}\text { proposing a global framework for } \\
\text { AGSD }\end{array}$ & a conceptual framework applicable in AGSD & $\begin{array}{l}\text { lack of framework validation in } \\
\text { real environments }\end{array}$ \\
\hline [34] & AGSD using social networks & $\begin{array}{l}\text { proposing Agile communication-related practices } \\
\text { using communication tools of social networks }\end{array}$ & $\begin{array}{l}\text { failure to refer to the negative } \\
\text { points of using social networks in } \\
\text { the workplace }\end{array}$ \\
\hline [35] & $\begin{array}{l}\text { experimental study of global } \\
\text { industrial projects }\end{array}$ & $\begin{array}{l}\text { classifying projects into an Agile group and a } \\
\text { structured group and making a comparison between } \\
\text { them }\end{array}$ & $\begin{array}{l}\text { limitation of the comparison } \\
\text { criteria }\end{array}$ \\
\hline
\end{tabular}

As it has been shown in the existing research studies, all researchers have presented a solution for Agile deployment in the GSD, and have proposed models or frameworks in this regard, but none of them has investigated the quality and the way of deployment and adaptation to the AGSD. Obviously, presenting a solution alone regardless of how effective and successful it can be in deploying Agile in global teams will confuse teams in their next choices and application of different methods. The aim of the current research is to propose a solution to assess the quality of deployment and adaptation to the Agile methods in the GSD.

\section{RESEARCH METHODOLOGY}

In order to obtain the assessment model of Agile adaptation quality in GSD, the steps shown in Figure 1 were performed. First, the qualitative features that were applicable in this area in the view of previous researchers were extracted by reviewing the literature. Then a questionnaire containing these factors 
was provided and a community of professionals was asked to give their opinions to confirm or reject these factors in the form of a five-point Likert scale (1 to 5). After the final list of factors was determined, 13 software professionals with the experience of deploying Agile in distributed settings were asked to participate in a survey and weigh the selected features based on the analytic hierarchy process (AHP). In the next stage, the final model was developed and used in a case study.

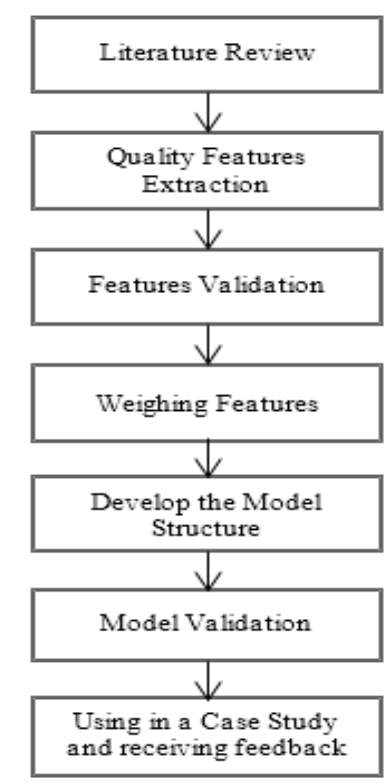

Figure 1. The research steps

\section{DATA ANALYSIS}

The review of the literature showed 20 qualitative factors in assessing the quality of adaptation to Agile in GSD. These factors can be divided into four main groups, as shown in Figure 2.

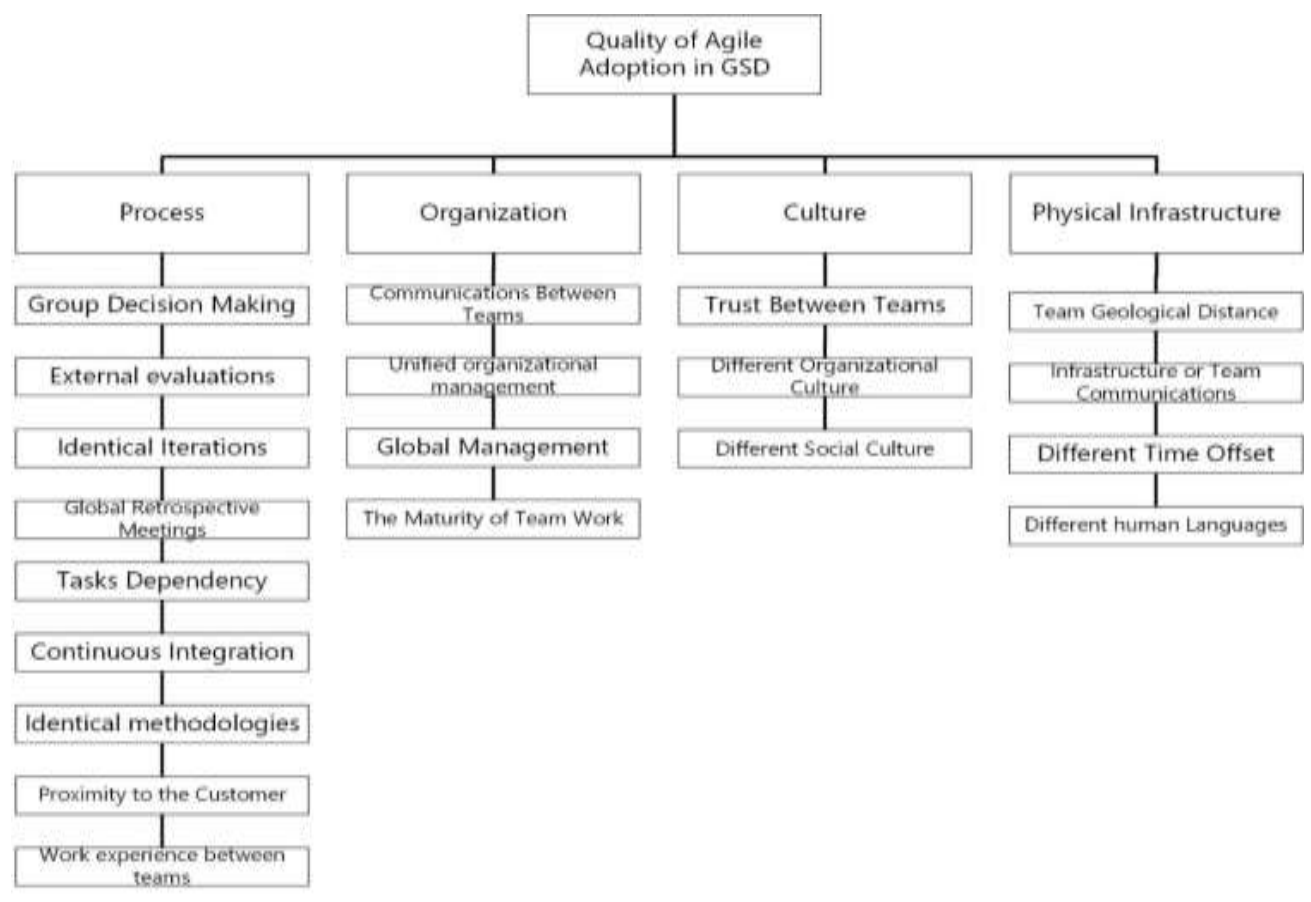

Figure 2. The appropriate qualitative criteria to assess the rate of success in adaptation to the AGSD 


\subsection{Features validation}

In order to validate the above-mentioned features, an electronic questionnaire was used and about 140 professionals with the experience of participating in ASD in the distributed settings were invited. The respondents gave their opinions on the validity of each of the criteria in the form of a number between 1 and 5. Following up repeatedly, finally, 103 responses were received. In order to investigate the questionnaire reliability, Cronbach's alpha test was used. According to this test, the alpha coefficient $>0.7$ indicates that the questionnaire reliability is acceptable. Table 2 shows the values of this coefficient for the selected factors. These values indicate the proper reliability of the questionnaire. The analysis of the received responses using SPSS showed that all qualitative factors have a mean higher than 3, indicating their approval by the research participates. Table 3 presents these values.

Table 2. Cronbach's alpha coefficient for selected features

\begin{tabular}{ccc}
\hline NO & Feature category & $\begin{array}{c}\text { Cronbach's alpha } \\
\text { coefficient }\end{array}$ \\
\hline 1 & process & 0.83 \\
2 & organization & 0.78 \\
3 & culture & 0.89 \\
4 & physical infrastructure & 0.92 \\
5 & all Features & 0.83 \\
\hline
\end{tabular}

Table 3. The mean and standard deviation of the value of qualitative features

\begin{tabular}{cccc}
\hline Category & Feature & Mean & Std. Dev \\
\hline process & group decision making & 4.1 & 0.31 \\
& external evaluations & 4.0 & 0.43 \\
& identical iterations & 4.4 & 0.32 \\
& global retrospective meeting & 4.5 & 0.32 \\
& task dependency & 3.7 & 0.54 \\
& continuous integration & 4.1 & 0.45 \\
& identical methodology & 3.7 & 0.65 \\
organization & proximity to customer & 4.3 & 0.62 \\
& work experience between teams & 3.3 & 0.29 \\
& communications between teams & 4.3 & 0.23 \\
& unified organizational management & 3.8 & 0.43 \\
culture & global management & 3.6 & 0.33 \\
& the maturity of teamwork & 3.7 & 0.2 \\
& trust between teams & 4.5 & 0.13 \\
physical & different organizational culture & 4.1 & 0.14 \\
infrastructure & different social culture & 4.3 & 0.44 \\
& team geological distance & 4.1 & 0.33 \\
& infrastructure of team communications & 3.6 & 0.42 \\
& different time offset & 3.7 & 0.32 \\
& different human language & 3.4 & 0.44 \\
\hline
\end{tabular}

\subsection{Features weighing}

Features were weighed using the professionals' opinions after confirming features validation. This stage was performed using the AHP technique. To this purpose, 13 professionals with proper experience in the research area were asked to help. Considering features classification, it was required to assign specific weight to each of the variables in their group. This weight was assigned due to the pair-wise comparison of each variable with members of its family by professionals. According to multi-criteria AHP principles, the weight of the comparison between the two variables was between 1 and 9. Data received from these researchers were analyzed using expert choice software. The above-mentioned software used to analyze the received data is one of the most well-known tools in this area. The proposed classifications, and after that, the validated features were asked from professionals like the following example.

\begin{tabular}{|l|l|l|l|l|l|l|l|l|l|l|l|l|l|l|l|l|l|l|}
\hline $\mathrm{A}$ & 9 & 8 & 7 & 6 & 5 & 4 & 3 & 2 & 1 & 2 & 3 & 4 & 5 & 6 & 7 & 8 & 9 & $\mathrm{~B}$ \\
\hline
\end{tabular}

In order to validate the obtained results from the AHP technique, an index called "inconsistency rate" is considered. If this index is less than 0.1 , there is an acceptable consistency between data and the results of the analysis. The received data analysis showed that the above-mentioned index is less than 0.1 . Table 4 displays the groups' weights and qualitative model factors. 
Table 4. Weighing features of the assessment of agile processes deployment in distributed settings

\begin{tabular}{|c|c|c|c|}
\hline Category & Weight & Feature & Weight \\
\hline \multirow[t]{9}{*}{ process } & 0.076 & group decision making & 0.03 \\
\hline & & external evaluations & 0.05 \\
\hline & & identical iterations & 0.203 \\
\hline & & global retrospective meeting & 0.122 \\
\hline & & task dependency & 0.143 \\
\hline & & continuous integration & 0.313 \\
\hline & & identical methodology & 0.028 \\
\hline & & proximity to customer & 0.049 \\
\hline & & work experience between teams & 0.063 \\
\hline \multirow{4}{*}{ organization } & 0.153 & communications between teams & 0.396 \\
\hline & & $\begin{array}{c}\text { unified organizational } \\
\text { management }\end{array}$ & 0.271 \\
\hline & & global management & 0.242 \\
\hline & & the maturity of teamwork & 0.091 \\
\hline \multirow[t]{3}{*}{ culture } & 0.387 & trust between teams & 0.78 \\
\hline & & different organizational culture & 0.14 \\
\hline & & different social culture & 0.08 \\
\hline & 0.385 & team geological distance & 0.09 \\
\hline \multirow[t]{3}{*}{ infrastructure } & & $\begin{array}{l}\text { the infrastructure of team } \\
\text { communications }\end{array}$ & 0.644 \\
\hline & & different time offset & 0.212 \\
\hline & & different human language & 0.053 \\
\hline sum & 1.00 & & \\
\hline
\end{tabular}

\subsection{Developing the qualitative model}

According to the calculated weights in the previous step, the qualitative assessment model under investigation can be developed. This model can be used in the form of a team self-declaration or by an external assessor. Table 5 shows the proposed model in this research and how to use it.

Table 5. The proposed model of qualitative assessment

\begin{tabular}{|c|c|c|c|c|c|}
\hline Category & Weight & Feature & Weight & $\begin{array}{c}\text { Self- } \\
\text { Declaration } \\
\text { Score }\end{array}$ & $\begin{array}{c}\text { Final } \\
\text { Weight }\end{array}$ \\
\hline \multirow[t]{9}{*}{ Process } & 0.076 & group decision making & 0.03 & & \\
\hline & & external evaluations & 0.05 & & \\
\hline & & identical iterations & 0.203 & & \\
\hline & & global retrospective meeting & 0.122 & & \\
\hline & & task dependency & 0.143 & & \\
\hline & & continuous integration & 0.313 & & \\
\hline & & identical methodology & 0.028 & & \\
\hline & & proximity to customer & 0.049 & & \\
\hline & & work experience between teams & 0.063 & & \\
\hline \multirow[t]{4}{*}{ Organization } & 0.153 & communications between teams & 0.396 & & \\
\hline & & unified organizational management & 0.271 & & \\
\hline & & global management & 0.242 & & \\
\hline & & the maturity of teamwork & 0.091 & & \\
\hline \multirow[t]{3}{*}{ Culture } & 0.387 & trust between teams & 0.78 & & \\
\hline & & different organizational culture & 0.14 & & \\
\hline & & different social culture & 0.08 & & \\
\hline \multirow{4}{*}{$\begin{array}{c}\text { Physical } \\
\text { infrastructure }\end{array}$} & 0.385 & team geological distance & 0.09 & & \\
\hline & & $\begin{array}{l}\text { the infrastructure of team } \\
\text { communications }\end{array}$ & 0.644 & & \\
\hline & & different time offset & 0.212 & & \\
\hline & & different human language & 0.053 & & \\
\hline Total Weight Score & & & & & \\
\hline
\end{tabular}

\subsection{Application of the model in a case study and receiving feedback}

The above-mentioned model was used in a software company with three different sites. Though due to limitations to the selection of such companies, this company was not a multinational company and acted only in three different sites in the country, the results and received feedbacks were however important, indicating that this assessment model is properly welcomed. These cases are mentioned in the following.

One of the senior professionals of the company was asked to comment on the status of the company regarding the deployment of Agile processes. Of course, this comment merely investigates factors associated 
with GSD and does not embrace items and factors related to inter-team and inter-organization cases. The result of this assessment is shown in Table 6 .

The final weight is obtained by multiplying the weight of the group * the weight of criteria * the weight of self-declaration. As shown in the above table, the self-assessment score of this company is 7.028 out of 10 , indicating the relative success of this company in the Agile processes deployment in its three sites. In the following, the obtained table was given to 5 cases of the company members ( 3 scrum master and 2 technology managers) who somehow navigated three sites, and they were asked to give their opinion with regard to the self-assessment results. Considering the reality of the obtained assessment score, all five persons believed that the score obtained from self-assessment indicates the reality of the quality level of the Agile processes deployment at their company level. In their view, if the ideal conditions are considered, the obtained score is fair and shows the current reality in that organization.

Table 6. A self-assessment of agile deployment quality in a multi-sites company

\begin{tabular}{|c|c|c|c|c|c|}
\hline Category & Weight & Feature & Weight & $\begin{array}{c}\text { Self- } \\
\text { Declaration } \\
\text { Score } \\
\end{array}$ & $\begin{array}{c}\text { Final } \\
\text { Weight }\end{array}$ \\
\hline \multirow[t]{9}{*}{ Process } & 0.076 & group decision making & 0.03 & 8 & 0.018 \\
\hline & & external evaluations & 0.05 & 3 & 0.011 \\
\hline & & identical iterations & 0.203 & 10 & 0.154 \\
\hline & & global retrospective meeting & 0.122 & 8 & 0.074 \\
\hline & & task dependency & 0.143 & 5 & 0.054 \\
\hline & & continuous integration & 0.313 & 0 & 0 \\
\hline & & identical methodology & 0.028 & 10 & 0.021 \\
\hline & & proximity to customer & 0.049 & 5 & 0.019 \\
\hline & & work experience between teams & 0.063 & 10 & 0.048 \\
\hline \multirow[t]{4}{*}{ Organization } & 0.153 & communications between teams & 0.396 & 10 & 0.606 \\
\hline & & $\begin{array}{l}\text { unified organizational } \\
\text { management }\end{array}$ & 0.271 & 10 & 0.415 \\
\hline & & global management & 0.242 & 8 & 0.296 \\
\hline & & the maturity of teamwork & 0.091 & 8 & 0.111 \\
\hline \multirow[t]{3}{*}{ Culture } & 0.387 & trust between teams & 0.78 & 6 & 1.811 \\
\hline & & different organizational culture & 0.14 & 10 & 0.542 \\
\hline & & different social culture & 0.08 & 10 & 0.31 \\
\hline Physical & 0.385 & team geological distance & 0.09 & 8 & 0.277 \\
\hline \multirow[t]{3}{*}{ infrastructure } & & $\begin{array}{l}\text { infrastructure of team } \\
\text { communications }\end{array}$ & 0.644 & 5 & 1.24 \\
\hline & & different time offset & 0.212 & 10 & 0.816 \\
\hline & & different human language & 0.053 & 10 & 0.204 \\
\hline Total weight score & & & & & 7.028 \\
\hline
\end{tabular}

\section{CONCLUSION}

The assessment of teams' success in adapting to Agile is one of the concerns of software teams and companies. This is particularly considered in the GSD in which the teams are in sites and sometimes different countries. The environmental conditions of the GSD make it difficult to adapt to Agile due to its inherent characteristics. Therefore, the existence of the assessment model to measure the success rate of adaptation to Agile in GSD can help teams measure the quality of Agile deployment. In the current research, at first, the main qualitative factors of the assessment of Agile adaptation in distributed settings were identified, and then, were classified in four classes of process, organization, culture, and physical infrastructure. These features were approved by professionals in a survey, and in the next step, the weight of each feature was extracted using the AHP technique. This way, a qualitative model was developed to assess the quality of the adaptation to Agile in global development and was used considering the positive feedback from ready professionals. In the last step of the study, this model was applied in a case study.

\section{REFERENCES}

[1] P. Abrahamsson, O. Salo, J. Ronkainen, and J. Warsta, "Agile software development methods: Review and analysis," arXiv preprint arXiv:1709.08439, 2017.

[2] K. Beck, A. Cockburn, R. Jeffries, and J. Highsmith, "Agile manifesto," [Online] Available: http://www.agilemanifesto.org, (2001, Feb. 2016).

[3] S. R. Jan, F. Dad, N. Amin, A. Hameed, and S. S. A. Shah, "Issues in global software development (communication, coordination and trust)-a critical review," IJSRSET, vol. 2, no. 2, 2016.

[4] A. Singh, K. Singh ,and N. Sharma, "Agile in global software engineering: an exploratory experience," International Journal of Agile Systems and Management, vol. 8, no. 1, pp. 23-38, 2015. 
[5] A. Alsahli, H. Khan, and S. Alyahya, "Agile Development Overcomes GSD Challenges :A Systematic Literature Review," International Journal of Computer Science and Software Engineering, vol. 6, no. 1, pp. 7-18, 2017.

[6] J. D. Herbsleb and D. Moitra, "Global software development," IEEE software, vol. 18, no. 2, pp. 16-20, 2001.

[7] J. H. Sharp and S. D. Ryan, "Global agile team configuration," Journal of Strategic Innovation and Sustainability, vol. 7, no. 1, pp. 120, 2011.

[8] V. Gomes and S. Marczak, "Problems? we all know we have them. do we have solutions too? a literature review on problems and their solutions in global software development," in Global Software Engineering (ICGSE), 2012 IEEE Seventh International Conference on, 2012, pp. 154-158: IEEE.

[9] J. Noll, S. Beecham, A. Razzak, B. Richardson, A. Barcomb, and I. Richardson, "Motivation and Autonomy in Global Software Development," in International Workshop on Global Sourcing of Information Technology and Business Processes, pp. 19-38: Springer, 2017.

[10] A. A. Khan and J. Keung, "Systematic review of success factors and barriers for software process improvement in global software development," IET software, vol. 10, no. 5, pp. 125-135, 2016.

[11] T. J. Gandomani and M. Z. Nafchi, "Agile transition and adoption human-related challenges and issues: A Grounded Theory approach," Computers in Human Behavior, vol. 62, pp. 257-266, 2016.

[12] T. J. Gandomani and M. Z. Nafchi, "An empirically-developed framework for Agile transition and adoption: A Grounded Theory approach," Journal of Systems and Software, vol. 107, pp. 204-219, 2015.

[13] A. R. Khan, R. Akbar, and D. Tan, "A Study on Global Software Development (GSD) and Software Development Process in Malaysian Software Companies," Journal of Telecommunication, Electronic and Computer Engineering (JTEC), vol. 8, no. 2, pp. 147-151,.2016

[14] N. K. Kamaruddin, N. H. Arshad, and A. Mohamed, "Chaos issues on communication in Agile Global Software Development," in 2012 IEEE Business, Engineering and IndustrialApplications Colloquium, BEIAC 2012, Kuala Lumpur, pp. 394-398, 2012.

[15] S .Jalali and C. Wohlin, "Global software engineering and agile practices: a systematic review," Journal of software: Evolution and Process, vol. 24, no. 6, pp. 643-659, 2012.

[16] R. Sriram and S. Mathew, "Global software development using agile methodologies: A review of literature," in Management of Innovation and Technology (ICMIT), 2012 IEEE International Conference on, pp. 389-393: IEEE, 2012.

[17] B. Ramesh, L. Cao, K. Mohan, and P. Xu, "Can distributed software development be agile?," Communications of the ACM, vol. 49, no. 10, pp. 41-46, 2006.

[18] D. Šmite, N. B. Moe, and P. J. Ågerfalk, "Fundamentals of agile distributed software development," in Agility Across Time and Space: Springer, pp. 3-7, 2010.

[19] R. Akbar, M. Haris, and M. Naeem, "Requirement gathering and tracking process for distributed agile based development," in Proceedings of the 8th Conference on Recent Advances in Computer Engineering, pp. 429-436, 2008.

[20] T. J. Gandomani, H. Zulzalil, A. A. A. Ghani, A. M. Sultan, and M. Z. Nafchi, "Obstacles to moving to agile software development; at a glance," Journal of Computer Science, vol. 9, no. 5, pp. 620-625, 2013.

[21] D. Leffingwell, Scaling software agility: best practices for large enterprises, Pearson Education, 2007.

[22] M. Mousaei and T. J. Gandomani, "A New Project Risk Management Model based on Scrum Framework and Prince2 Methodology," International Journal of Advanced Computer Science and Applications (IJACSA), vol. 9, no. 4, 2018.

[23] F. Ghafoor, I. A. Shah, and N. Rashid, "Issues in adopting agile methodologies in global and local software development: A systematic literature review protocol with preliminary results," International Journal of Computer Applications, vol. 160, no. 7, 2017.

[24] I. Richter, F. Raith, and M. Weber, "Problems in agile global software engineering projects especially within traditionally organised corporations:[An exploratory semi-structured interview study]," in Proceedings of the Ninth International $C^{*}$ Conference on Computer Science \& Software Engineering, pp. 33-43: ACM, 2016.

[25] P. Bjørn, A.-M. Søderberg, and S. Krishna, "Translocality in Global Software Development: The Dark Side of Global Agile," Human-Computer Interaction, pp. 1-30, 2017.

[26] T. J. Gandomani, h. Zulzalil, A. Javanmardi, A. A. A. Ghani, A. B. M. Sultan, and M. Z. Nafchi, "How pre-start up assessment helps software companies in Agile transition," Science International-Lahore, vol. 25, no. 4, pp. 11251130, 2013.

[27] T. J. Gandomani, H. Zulzalil, A. A. Abd Ghani, A. B. M. Sultan, and K. Y. Sharif, "Exploring Facilitators of Transition and Adoption to Agile Methods: a Grounded Theory Study," Journal of Software, vol. 7, no. 9, pp. 1666-1678, 2014.

[28] T. J. Gandomani, H. Zulzalil, A. A. A. Ghani, A. B. M. Sultan, and K. Y. Sharif, "An Exploratory Study on Managing Agile Transition and Adoption," in Recent Advances in Information and Communication Technology, vol. 265, pp. 177-188, Springer, 2014.

[29] T. J. Gandomani and M. Z. Nafchi, "Agile Coaches and Champions: Two Hidden Facilitators of Agile Transition," in Emerging Innovations in Agile Software Development: IGI Global, pp. 24-36, 2016.

[30] T. Dreesen, R. Linden, C. Meures, N. Schmidt, and C. Rosenkranz, "Beyond the border: a comparative literature review on communication practices for agile global outsourced software development projects," in System Sciences (HICSS), 2016 49th Hawaii International Conference on, pp. 4932-4941: IEEE, 2016.

[31] R. Vallon, B. J. da Silva Estácio, R. Prikladnicki, and T. Grechenig, "Systematic literature review on agile practices in global software development," Information and Software Technology, vol. 96, pp. 161-180, 2018. 
[32] D. C. Kalluri, "Role of Agile Methods in Global Software Development," Dissertations and Theses, Harrisburg University of Science and Technology Digital Commons at Harrisburg University, Retrieved from https://digitalcommons.harrisburgu.edu/pmgt_dandt/25, 2017.

[33] R. Vallon, S. Strobl, M. Bernhart, R. Prikladnicki, and T. Grechenig, "ADAPT: A Framework for Agile Distributed Software Development," IEEE Software, no. 6, pp. 106-111, 2016.

[34] G. Lampropoulos and K. Siakas, "Communication in Distributed Agile Software Development: Impact of Social Media-Social Networking," SQM XXVI, pp. 43, 2018.

[35] H.-C. Estler, M. Nordio, C. A. Furia, B. Meyer, and J. Schneider, "Agile vs. structured distributed software development: A case study," Empirical Software Engineering, vol. 19, no. 5, pp. 1197-1224, 2014.

[36] F. Tahir and I. A. Manarvi, "Agile Process Model and Practices in Distributed Environment," in Concurrent Engineering Approaches for Sustainable Product Development in a Multi-Disciplinary Environment, Springer, pp. 1169-1180, 2013. 